Article

\title{
Food Democracy from the Top Down? State-Driven Participation Processes for Local Food System Transformations towards Sustainability
}

\author{
Jana Baldy * and Sylvia Kruse \\ Chair of Forest and Environmental Policy, University of Freiburg, 79106 Freiburg, Germany; \\ E-Mails: jana.baldy@ifp.uni-freiburg.de (J.B.), sylvia.kruse@ifp.uni-freiburg.de (S.K.) \\ * Corresponding author
}

Submitted: 15 March 2019 | Accepted: 12 August 2019 | Published: 28 October 2019

\begin{abstract}
Food democracy is a concept with growing influence in food policy research. It involves citizens regaining democratic control of the food system and enabling its sustainable transformation. In focusing mainly on civil society initiatives, food democracy research has so far neglected the potential of state-driven food-related participation processes. We base our study on qualitative interviews with local stakeholders in two smaller cities in southern Germany where the city administration and city council initiated participatory processes. The study aims to understand how local actors are framing state-driven participation processes concerning sustainable local food system transformation along key dimensions of food democracy. We identify eight categories that conceptually constitute food democracy: mutual knowledge exchange; legitimacy and credibility of knowledge claims; transparent processes for deliberating ideas; shared language for sharing ideas; expectations of and experience with efficacy; role model function of municipalities; raising awareness; and motivation and justification of the normative orientation. Furthermore, the empirical analysis shows that state actors can have important roles in food-related participation processes as potential initiators, shapers and implementers depending on how they interact with local food-related actors and how they design and coordinate food system transformation processes. This suggests that food democracy research should not necessarily conceptualize state actors, local entrepreneurs and citizens as opponents, but rather, should reconsider how these various actors can drive food democracy and citizenship in a supportive and coordinated way.
\end{abstract}

\section{Keywords}

food democracy; food policy; local food systems; participation; state actors; sustainability

\section{Issue}

This article is part of the issue "New Perspectives on Food Democracy" edited by Basil Bornemann (University of Basel, Switzerland) and Sabine Weiland (Université Catholique de Lille, France).

(C) 2019 by the authors; licensee Cogitatio (Lisbon, Portugal). This article is licensed under a Creative Commons Attribution 4.0 International License (CC BY).

\section{Introduction}

Food democracy is a concept with growing influence in food policy research (Booth \& Coveney, 2015; Hassanein, 2003, 2008; Lang, 2005; Perrett \& Jackson, 2015; Renting, Schermer, \& Rossi, 2012). Following an identified shift in food policy from state control to growing power of large corporations over the food system, food democracy is part of a trend where "demands from below" (Lang, 1999, p. 218) are given a voice and citizens regain control over the food system (Hassanein, 2003; Lang, 2005). Lang, Barling, and Caraher (2009, p. 67) argue that "the success of public policy on food depends upon successful engagement with the actors across the food system from food producers to consumers and those who figure inbetween." Consequently, food policy needs to be developed through a triangular collaboration between state actors, economic actors and civil society (Lang, 2005, p. 730). This means that these three groups of actors are understood to be equally important with regard to food system change.

To date, food democracy research has focused on civil society movements and the role of citizens (Hassanein, 2003; Johnston, Biro, \& MacKendrick, 2009) while ne- 
glecting the two other parts of the triangle. Nevertheless, state actors at the local level (e.g., elected members of the city council and members of the city administration) are core actors in various food policy initiatives aiming at sustainability, such as the development of sustainable urban food strategies (Hebinck \& Page, 2017) or as shapers of "creative city politics" (Cretella \& Buenger, 2016) concerning food system transformation. Already in 1999, Lang (1999, p. 220) argued that "[a] rethinking of the state's role in food is long overdue." Almost ten years later, Mendes (2008, p. 947) underlined that "we are now entering a new phase of local state involvement in food policy, governance and policy-making characterized by proactive partnerships, with cities playing the role of facilitator, educator, and promoter of efficiencies."

Against this background, we identify a research gap: While the importance of municipalities in initiatives aiming at sustainable local food system transformation is growing, food democracy research mostly focuses on social movements and the role of citizens. This article addresses this gap by focusing on food-related participation processes initiated by local state actors.

It can be assumed that the importance of state actors in shaping food systems will continue to increase in the coming years, especially at the local level. Furthermore, the way in which local political processes are shaped is also changing. At the local level, a change towards more participation and deliberation has been observable for some years now (Turnhout, van Bommel, \& Aarts, 2010; Walk, 2008). In this context, administration and local policymakers are trying to involve actors from civil society and local economies in the policymaking process. With a special focus on top-down processes of food democracy, our research makes a relevant contribution to the body of knowledge regarding both food democracy and food policy: First, we identify the specific conditions, challenges and pitfalls of top-down initiated participation processes within food system transformation; second, we propose empirically grounded conceptual elements for food democracy from the top-down.

With our research, we aim to understand how local actors make sense of state-driven participation processes concerning sustainable local food system transformation along key dimensions of food democracy. Connected to this goal we aim to investigate the role of state actors in relation to food democracy and pose the following research question: How are local state-driven participation processes understood as food democracy?

Through an in-depth analysis of two cases in smaller cities in southern Germany where city administrations and local politicians initiated participatory processes in order to transform their local food systems in a sustainable way, we investigate how local actors frame these participation processes as processes of food democracy. Methodologically, we use the framing approach (Benford \& Snow, 2000) as a tool to provide deeper insights into how people make sense of the participation processes.
First, we introduce food democracy as a relevant concept for food policy research. In this context, we shed light on the role of citizens in food system transformation and explain the conceptualization of food democracy as it is used in this article. In the following, we focus on the methodology, describing the two cases on which our research is based and our interpretative methodological approach. In the results section, we link our research findings to the conceptualization of food democracy. Finally, we discuss the results, thereby focusing on the roles of state-actors in food-related participation processes and the conceptual implications for food democracy research. In the conclusion, we summarize our contributions to conceptualize food democracy and substantiate the significance of state actors within processes of food democracy.

\section{Food Democracy as a Concept for Food Policy Research}

In the following, we first delineate the changing role of citizens within food policy and then introduce a heuristic of food democracy along four key dimensions.

\subsection{The Role of Citizens in Food Policy and Sustainability Transformation of the Food System}

The notion of food democracy was introduced by food policy scholars in the 1990s "to highlight the great struggle over the centuries, in all cultures, to achieve the right of all citizens to have access to a decent, affordable, health-enhancing diet, grown in conditions in which they can have confidence" (Lang, 1998, p. 18). In the past, governments were responsible for food safety and security to ensure safe and healthy populations. This was especially important in the post-war period when hunger and malnutrition were omnipresent. The economic upswing in western European countries resulted in a situation where food security seemed to be ensured. Over the twentieth century, the food system became globalized and production, processing, trade and consumption were delocalized. This resulted in negative impacts on the environment and food security, especially in poorer countries. The core task of food policy changed from security to the much broader approach of sustainability, within which food security is subsumed (Lang \& Barling, 2012, p. 313).

Within the globalized food system, Lang et al. observe that governments no longer shape food policy; instead, "giant food and drink corporations...formulate their own food policies" $(2009$, p. 11) and their decisions elude democratic control. Food democracy thus evolved as a countermovement to balance power and control within food policy and the food system, especially on the local scale (Hassanein, 2003; Lang, 1998). Hassanein defines food democracy as a possibility and requirement for all citizens to actively engage in shaping the food system (2003, p. 83), while Lang stresses the need to rebal- 
ance control between citizens, state and economic actors over how food is produced, traded, processed and consumed (2005, p. 730). Other scholars emphasize the introduction of democratic principles such as participation, transparency and public deliberation as the main aim of food democracy: "[t]he concept of food democracy...defines food as a life good that should ideally exist within democratic control in the commons" (Johnston et al., 2009, pp. 524-525). Hassanein (2003, p. 83) proposes that only a democratically legitimized control of the local food system is able to effectively address the above-mentioned need for a transformation of the food system towards sustainability. Other related concepts of civil engagement in food policies investigating food policy councils (e.g., Schiff, 2008; Sieveking, 2019), food networks (e.g., Seyfang, 2006) or food citizenship (e.g., Wilkins, 2005) also stress this link between food democracy and food system transformations towards sustainability through the active, democratic engagement of citizens and civil society.

\subsection{Conceptualizing Food Democracy}

As this short review on the role of citizens in food policy and sustainability transformation of the food system shows, food democracy research has some conceptual common ground. Nevertheless, it lacks clarity and has been only poorly operationalized for empirical research. Hassanein (2008, pp. 290-291) is one of the few scholars who proposes a heuristic of four key dimensions that enable individuals' meaningful participation in food democracy processes. The first key dimension involves knowledge and becoming knowledgeable about food and food systems to shorten the distance between producer and consumer (Hassanein, 2008, p. 290). The second key dimension comprises sharing ideas, which involves clarifying and discussing food-related issues and values among participants with the effect that they can "make better decisions for both themselves and others" (Hassanein, 2008, p. 290). The third dimension is efficacy as the individuals' "capacity to determine and produce desired results" (Hassanein, 2008, p. 290). As regards food and the food system, this involves citizens' work to address and solve food problems. An orientation towards the community good is the fourth key dimension of food democracy. This involves caring about general well-being in a way that considers "both the human and non-human communities of place we inhabit" (Hassanein, 2008, p. 291). This dimension addresses different levels of the common good: the micro-level of individual or self-interest, the meso-level of community interest and caring for the local area, and the macro-level where participants frame their motivations and justifications with regard to nature, climate, environment and humanity in general. Hassanein further considers collaborating towards food system sustainability as a precondition given that "food democracy is not achieved solely by individual decisions and actions but necessarily involves collective action by and among organizations" (2008, p. 290). As a theoretical basis, Hassanein (2008, p. 290) draws on the criticism that representative or "thin" democracy does not offer enough possibilities to actively engage in decision-making processes in a meaningful way and produces less legitimate outcomes. Strong democracy on the other hand involves participatory engagement of citizens in policymaking, with citizens governing themselves as far as possible rather than delegating responsibility to representatives (Barber, 1984). For our research on state-driven participation processes for local food system transformations, we operationalize this four-dimensional framework, applying it as a heuristic and inductively developing categories for knowledge, idea-sharing processes, efficacy and normative orientations concerning the outcomes of participatory food democracy processes.

\section{Methodology}

In this section we introduce our case studies with a focus on the participation processes and present the methods used for data collection and analysis.

\subsection{Case Studies: Transformation of the Local Food Systems in Two Cities in Southern Germany}

This research was conducted in two smaller cities-each with around 20,000 inhabitants-located in southern Germany. For this publication, we call them A-town and B-town. As both cities had already engaged with climate issues and sustainability as well as, to some extent, with food as a topic of regional development, they were requested to become partners in a transdisciplinary project on food system transformation. As a result, both cities decided to transform their local food systems towards sustainability. According to the project design, the respective city administration and city council initiated a participation process with three dialog formats to discuss goals and measures leading to a sustainable transformation of the local food system (Annexes 1 and 2). Even though the integration of sustainable food as a topic on the local agenda was initiated by the transdisciplinary project, the dialog processes were shaped by the city administrations, starting with the recruitment of participants and concluding with the compilation of measures and goals and the implementation of concrete policy measures. Hence, the participation processes can be described as state-driven. Unlike many other food-related processes such as food policy councils, the impetus in our two cases did not come from the citizens, even though some citizens' initiatives such as urban gardening already existed in the two cities. The following dialog formats were used in both cities:

- Civil dialogs invited all citizens through different media (newspaper, homepage, billboards) to participate and develop measures and goals for the sustainable transformation of the local food system; 
- For the expert dialog, the city administration chose and personally invited the participants, who represented local businesses, environmental organizations and social agencies. This selection process was not made transparent by the city administration. However, it became obvious that the administration had selected people who seemed to be relevant actors for urban development and with whom they already had experience of positive cooperation. The participants developed and discussed goals and measures for transforming the local food system. In a closing meeting, goals and measures from both dialog formats were combined and discussed in order to prepare a final list for the steering group;

- The steering group meeting was initiated and moderated by the respective city administration. It included personally invited administrative staff and members of the city council, indicating that these roles were the primary selection criteria used by the city administration. The aim was to discuss the goals and measures proposed by the civil and expert dialogs and to select or modify these before voting on them.

In both cities, the proposed goals and measures were discussed and put to vote in official city council meetings. These included measures such as support of urban gardening initiatives and ecological farming, cooking courses, making the weekly market more attractive, or including food as a topic in a holiday program for children.

\subsection{Methods for Data Collection and Analysis}

As mentioned in the case description, neither of the cities had previously been familiar with food-related participation and transformation processes at the local level. Against this background, we chose an interpretative approach to focus on how participants make sense of the emerging transformation of food system and policy. We use framing as an analytic tool in the analysis (Benford \& Snow, 2000; van Hulst \& Yanow, 2016). Benford and Snow (2000) conceptualize their framing approach with a special focus on the development of social movements. Their analysis of framing problems (diagnostic framing), solutions (prognostic framing) and motivations enables understanding of how individuals engage in policy processes. In both cities, we conducted participatory observations and semi-structured interviews with local actors who directly engaged in one of the three dialog formats or who were indirectly involved. The presented research is based on 36 interviews (Annexes 3 and 4).

The interviews were transcribed and analyzed following a reconstructive procedure (Kruse, 2015; Przyborski \& Wohlrab-Sahr, 2014) using the analysis software MAXQDA. The use of reconstructive procedures is necessary since this approach facilitates the identification of structures of meaning. We combined deductive and in- ductive coding. Starting with the key dimensions of food democracy developed by Hassanein, we identified different kinds of framing. In a second step, we went deeper into the passages in which the interviewees described or evaluated the participation processes. Our inductive approach explored how interviewees were framing the participation process according to the four heuristic dimensions of food democracy (Section 2). Using an inductive approach, we identified new categories that are not part of Hassanein's conceptualization of food democracy. In the analysis and interpretation, we considered similarities and differences between the two cases and between the different groups of actors.

\section{Results: Framing of the State-Driven Participation Processes of Local Food System Transformation}

In the result section, we analyze the framing of the statedriven participation processes of local food system transformation. The framings of local actors will thereby be linked to the four key dimensions of food democracy: knowledge, sharing ideas, efficacy and orientation towards community good (Hassanein, 2008). As an outcome of our analysis, we conclude that these four dimensions can be substantiated by eight categories of food democracy derived from our analysis representing how interviewees are framing state-driven participation processes.

\subsection{Knowing the Food System}

The analysis of the participation processes shows that knowledge about food and the food system is both a starting point as well as an outcome of food democracy processes and thus a central element of these. Interviewees emphasize that mutual exchange of knowledge about local food systems is an important basis for true deliberation within the participation processes. This not only involves sharing different forms of knowledge among diverse food-related actors who would otherwise not come together (e.g., members of urban gardening initiatives, city planners, farmers, cooks and heads of nursing homes), but it also addresses the problem that lacking knowledge about the local food system hinders actors from participating in transformation processes in the first place and risks excluding issues relevant to a sustainable food system: "We were not aware that...[food] was also a topic that...had a very important influence on our $\mathrm{CO} 2$ emissions" (Interviewee A17). This quote illustrates that not all members of the city administration were even aware of the climate impacts of food before starting the participation process. Meanwhile, the analysis revealed a high level of contestation among participants regarding what issues should be included in mutual knowledge exchange. Additionally, some interviewees were very open to mutual learning, while others assumed that they already had all the relevant knowledge about sustainable food system transformations. 
Legitimacy and credibility are a second core framing of knowledge as a dimension of food democracy processes. During the participation processes, the question was raised as to which actors can legitimately organize and take part in the participation process and thereby gain the chance to bring their knowledge into the deliberation of ideas. Connected to these questions is the credibility of knowledge. Interestingly, actors from local food businesses as well as civil society actors question the credibility of the knowledge claims of the other party, accusing them of hidden goals or values. While interviewees from civil society organizations assume that local entrepreneurs are only engaging because they expect personal profit, interviewees from local businesses assume that civil society actors advocate growth-critical positions. For many interviewees, two types of knowledge were especially credible: knowledge of like-minded participants and scientific knowledge, especially if this could be used to underpin their own opinions.

\subsection{The Process of Sharing Ideas about the Food System}

Transparency and the degree of openness of the deliberation process are considered crucial within the participatory process of local food system transformation. The analysis shows that many interviewees consider openness and the exchange of issues and ideas at eye level to be important prerequisites for true deliberation and dialog, thereby criticizing rigidly structured, one-way procedures. Another emphasized prerequisite for mutual exchange is transparency in both the design and outcomes of the debate.

Another transparency issue was who participated in the three formats; interviewees emphasized that it was important for participants to know who else would or would not engage. This also helped participants to reflect on their own role within the participation process. While some questioned whether they were the right person to address the issues discussed (Interviewee B25), others considered themselves to be "chosen" experts (Interviewee A16) as they had been selected by the hosting city administration.

The second relevant aspect for sharing ideas on local food system transformation is a shared language. It was criticized that the language used during the participation process was partly too scientific and hindered the engagement of citizens and other stakeholder groups.

\subsection{Expected Efficacy and the Role of Administrations}

In both cities, many interviewees did not expect much efficacy from the participation processes in general. Some expected the outcome to become a "drawer concept" (Interviewee A13), representing the interviewees' fear that the outcomes would metaphorically disappear into a drawer rather than be implemented in practice. Others were explicitly skeptical about the quality of the result and its capacity to achieve changes in the local food sys- tem (cf. Interviewees B5, B15). One reason for limited expectations is a perceived deficit within the participation process, especially concerning the mutual exchange of knowledge and ideas. Other reasons involve negative experiences with previous participation processes: "I have already accompanied many such projects. And apart from a lot of foam there is usually nothing left" (Interviewee B9, cf. B24). Finally, the city administrations initiating the processes were not expected to have enough influence on relevant policy levels or on significant sectors, for instance on agricultural policy.

Despite the identified problem framing concerning a perceived lack of agency, city authorities are considered pivotal for affecting change through participation processes. Interviewees from city authorities and from other stakeholder groups emphasized that the administration has a role-model function for local citizens: "if we don't manage to change the school meals in our canteen...where the city has a direct influence... then we have failed" (Interviewee A24). Though sustainable food system transformation at the local level is a relatively new issue for public actors, many interviewees demanded that the city administration use its scope for action, e.g., in the field of school nutrition and public procurement, to achieve increasing sustainability or at least increasing regionality within the local food system.

Another element of efficacy is raising awareness of local food systems and the need for a transformation towards sustainability. Despite the limited expectations of the participation process, raising awareness is a possible and important outcome for some interviewees. Others call attention to the dilemma that knowledge and awareness do not necessarily lead to desired action. In the two cases, awareness raising in general is a key solution framing, regardless of whether the problem framing focuses on economic, environmental or social aspects.

\subsection{Justifying Different Orientations within the Food System}

The analysis shows that stakeholders justify their participation and frame the need to transform the local food system in different ways depending on their respective backgrounds and roles. We identify three different levels of framing. At the micro-level, interviewees frame their own participation or the participation of other stakeholders with reference to particular individual interests and partly self-interest. This is especially true for local business actors (Interviewees B25, B12). One interviewee revised his assumption about his co-participants who he had initially described as being oriented by self-interest (Interviewee A16). This shows that learning takes place within participation processes, which can increase credibility and trust among diverse and partly opposing participants.

At the meso-level, interviewees stress their orientation towards the community good, believing local food system transformation could positively influence their 
city's development. It is apparent here that most interviewees relate their motivation to support the community good to their role and responsibilities as citizens. At the macro-level, interviewees frame their motivation with reference to environmental goals, sustainability and climate change, justifying their participation with the need for a food system transformation (Interviewee A17). Interestingly, some interviewees frame their motivation on multiple orientation levels, even taking into account inconsistencies (e.g., self-interest at the microlevel while supporting the community good at the mesolevel). It becomes obvious that the interviewees primarily refer to the kind of framing that relates to their professional life. However, their framing is also related to their everyday life and connected to a broader context. The use of different kinds of framing drawing on different levels of argumentation illustrates the high complexity of the topic.

\section{Discussion: Food Democracy from the Top-Down}

In our research, we focused on the framing of statedriven participation processes of local food system transformation. In the following, we discuss (1) implications for the roles of state-actors in food-related participation processes, (2) conceptual implications of our results for food democracy research and (3) prospects for further research.

\subsection{State-Actors within the Triangle of Food Policy Actors}

Based on our results, we identify three roles that stateactors can adopt in food-related participation processes and a set of influential context factors.

First, as initiators of processes, state actors have the possibility to introduce citizens to the topic, motivate and justify food-related transformation with an orientation towards community good and create legitimacy of the process. State-driven processes seem to have the potential to address a broader variety of citizens and economic actors than processes initiated by citizens only, as in the case of some food policy council initiatives (e.g., Clark, 2018). However, in their study of food policy in Ede, van de Griend, Duncan, and Wiskerke (2019) stress that the activation of different groups of citizens "remains one of the main challenges." In our cases, some members of civil society negotiate food-related topics with regard to changes in the economic system, while there are economic actors who explain their motivation to take part in food-related participation processes in terms of their own economic interest. As shown in the results section, this stereotypical categorization does not fit all actors. Nevertheless, in both cities, all groups of actors assume that there is a link between group membership and argumentative strategy. As a result, municipal and business actors perceive civil society actors as having stronger values and a rather low willingness to compromise. Due to their role as initiators, state actors in general have the unique potential to act as mediators between these different motivations and justifications. However, there is a risk of imbalance from the start where the initiator of a food transformation process is not sufficiently open to the knowledge, ideas and normative orientations of all food-related actors in the city.

The second role state-actors can take on is that of shapers of the process, e.g., by deciding who is involved in the mutual knowledge exchange and in the sharing of ideas based on different normative orientations and by creating transparency within the process. The results show that although the participation processes in both cases were structured in the same way, they were evaluated differently in relation to the perception of mutual exchange and transparency. In A-town, participants perceived themselves as "chosen" and considered the process to be sufficiently open and transparent to exchange knowledge and share ideas. In B-town, participants of the civil and expert dialog criticized a lack of transparency regarding the selection of participants. Furthermore, they criticized the moderation and procedure and actively demanded more deliberative elements to facilitate a dialog at eye level. This implies that for the shapers of the process, not only is the process design pivotal but also the degree to which they are trusted and considered by participants to be credible.

In their role as implementers, state actors can be role models when they implement food policy measures themselves. They can, for instance, coordinate and support implementation of other actors by strengthening the interaction within the triangle of state actors, economic actors and citizens/civil society. As our results show, the participants do not have high expectations regarding possible outcomes. This is due, on the one hand, to negative previous experiences with urban participation processes and, on the other hand, to the perception that the municipality itself lacks sufficient agentive capacity. In a previous article, it has been discussed how this perceived lack of agency can result in a process of individualization of responsibility concerning food system change (Baldy, 2019). However, the role of the city as implementer shows that the perceived lack of agency does not necessarily mean that the municipal actors actually lack agentive capacities. Particularly as role models, municipal actors can support an orientation towards the community good by facilitating the interaction of all relevant actors. Van de Griend et al. (2019) underline the particular importance of state actors in local food policy, claiming that:

A strong leadership (top-down) role for the municipality can raise awareness about food system problems, increase knowledge amongst citizens by putting a topic on the agenda and creating spaces in which food actors can meet and generate political will for food system change. (van de Griend et al., 2019) 
Following our argumentation, this addresses especially what we call the role model function of municipalities. Furthermore, the results imply that the political, socioeconomic and historical contexts in which state actors initiate, shape and implement food-related transformation processes are highly relevant for the framing of the process. One of these contextual factors is regional identity, which seems very relevant for differences in political culture. In A-town, located in a rural area with a traditional value system, a tendency towards cooperative and consensus-oriented involvement of actors was observed. In contrast, B-town is located close to a larger city and is therefore shaped by a more highly fluctuating of the population and a less integrative political culture. The importance of "interpersonal social effects, which include relationships between people, group identities and associations, as well as economic exchanges" (Baker, 2011, p. 10) seems to become especially obvious in food-related initiatives at the local level.

Another important contextual factor we identified is that, in both cases, previous experiences with participation processes shaped the actors' low expectations of efficacy with negative consequences for both motivation and the perceived credibility of the actors. In B-town, for example, civil society members expressed rather critical assessments of the local political system's efficacy, thereby referencing previous attempts to achieve changes in local politics that were not supported by local politicians; correspondingly, the municipal actors stated that they would not cooperate with certain actors with whom they had previously negative experiences. As other studies have also shown, this can develop into a severe barrier for state-driven participation processes as the experience of efficacy is a core element of strong democracy (Booth \& Coveney, 2015). Participation processes without efficacy might appear to be symbolic politics only and low policy impacts can lead to increasing political disenchantment (Schaal \& Wilhelm, 2018, pp. 206-207). These insights suggest that previous experiences of appreciation and efficacy, as well as regional identity, influence the political culture and thus the relationships between local authorities, civil society and economic actors.

Summarizing, it becomes apparent in our two cases that, concerning the food policy triangle of state, economy and civil society, the conceptualization of active citizens versus an undemocratic economy in food democracy research needs to be questioned. In both our cases, we encountered initiatives of food system transformations that were neither initiated from within the organized participation processes, nor by citizens' initiatives, but rather by influential business actors. Initiatives such as a regional catering company, a cooperative for strengthening regional food production, and the establishment of regional labels through mergers of production, processing and trade companies are initiated as economic activities where profit is one goal, next to the community's well-being. They explicitly aim to increase re- gional production and additionally to make the local food system more sustainable or healthy. In most cases, these local entrepreneurs act independently from, but in agreement with, the public administration.

\subsection{Conceptual Implications for Food Democracy Research}

The identified roles of state actors within food-related participation processes influence the existing conceptualization of food democracy. Starting with the four key dimensions of food democracy by Hassanein (2008, pp. 290-291), we derived an empirically substantiated concept with eight categories for the analysis of statedriven participation processes, thereby deepening the current understanding of food democracy. (1) Mutual exchange of knowledge and (2) the legitimacy and credibility of knowledge claims are essential for knowing the food system, while (3) transparency and (4) shared language are identified as crucial categories within the process of sharing ideas. A shared language is also an important condition of sharing ideas. From the actors' viewpoint, (5) expectations and experiences of previous participation processes determine the efficacy of the process, as do (6) municipalities acting as role models and (7) raising awareness of citizens. Actors' orientation within the food system depends on their (8) motivations and justifications. This set of categories helps to analyze statedriven participation processes and shifts the current understanding of food democracy from focusing on transformative actors only to a broader range of food democracy processes including the active involvement of state actors. Thus, our insights can, for example, be transferred to research on food networks (Hebinck \& Page, 2017) or food policy councils at the local level as well as to both sites of interest: food democracy and food policy scholars (Lang, 2005; Schiff, 2008).

A second important implication for academic research relates to food democracy as a deliberative process. In line with other scholars in participation research (Baasch \& Blöbaum, 2017, p. 17), Hassanein (2008, p. 290) assumes that deliberative elements are more democratic per se; our results question this. They rather show that the way in which stakeholders assess deliberative participation design critically depends on previous experiences with participation processes and the actors involved, as well as on their feelings of mutual trust, credibility and legitimacy.

\subsection{Further Research}

In this article, we developed an empirical grounding for the concept of food democracy by building on an interpretative analysis of food-related participation processes in two specific cases. Since our analysis and development of the food democracy framework is based specifically on two cases of smaller cities in southern Germany, the results cannot be generalized for food-related participa- 
tion processes in smaller cities in general. To strengthen the robustness and transferability of our results, we suggest further research in other cities of different sizes in Germany and in countries with similar economic and political circumstances. The identified conceptual categories of food democracy need further development and deeper investigation of the relationship between state actors and other actors that reflect concepts of political cultures (Almond \& Verba, 1963) and regional identity (Paasi, 2009). Further, we suggest linking the concept of food democracy more strongly to concepts identified in deliberative participation processes and participative governance research (Fischer, 2006, 2012; Turnhout et al., 2010; van der Heijden, 2018; Walk, 2008). For example, Fischer (2012, p. 464) assumes that "politicalcultural and pedagogical strategies can facilitate the deliberative empowerment in participatory governance." Together with an emphasis on the importance of power relations and civic engagement within participation processes (Walk, 2008, pp. 17-18) a further connection to concepts of political culture seems highly relevant for the evolution of food democracy in both bottom-up and topdown processes, which could complement the concept of food democracy.

\section{Conclusion}

This article focused on the role of local state actors within food-related participation processes and has dealt with the question of how these state-driven processes can be described as processes of food democracy. Our results indicate that state actors play an important role in food-related participation processes as potential initiators, shapers and implementers, depending on how they interact with local food-related actors and how they design and coordinate the process of food system transformation within the context of the specific political culture and regional identity of the city. Credibility is one of the most important factors. Ideally, state actors are considered to be neutral, which offers the opportunity to mediate between economic interests and the interests of civil society. However, the comparison of the two cases shows that the extent to which state actors are accepted as neutral depends on the respective political culture. For academic research, this implies that the concepts of citizenship and democracy, and how these have been applied in food democracy literature to date, need to be reconsidered. Instead of conceptualizing state actors, economic actors and citizens as opponents, our study suggests that food democracy depends on supportive state actors, facilitating interactions between all groups of relevant actors in order to drive the transformation of local food systems. Furthermore, this article contributes to the conceptualization of food democracy in food policy research. Based on four dimensions of food democracy (Hassanein, 2008), we developed an empirically substantiated concept with eight categories for the analysis of state-driven participation processes.
Practical implications of this research for state-driven transformations of local food systems towards sustainability include: a need for state actors to reflect on their own roles when initiating and designing food related participation processes; to create a constructive and trustful atmosphere to foster transparency and credibility among the actor groups; to act as potential role models for sustainability transformation; and to draw together food-related initiatives that take place simultaneously and separately from the top-down initiated participation processes.

\section{Acknowledgments}

The research was founded by the Federal Ministry of Education and Research (BMBF-Bundesministerium für Bildung und Forschung) within the programme Research for Sustainable Development (FONA-Forschung für Nachhaltige Entwicklung; Grant Number 01UR1614A). The article processing charge was funded by the German Research Foundation (DFG) and the University of Freiburg in the funding programme Open Access Publishing. We thank all interviewees and stakeholders for their time and openness. And we are grateful to the anonymous reviewers and the academic editors, whose comments helped us to improve the article considerably.

\section{Conflict of Interests}

The authors declare no conflict of interests.

\section{References}

Almond, G. A., \& Verba, S. (1963). The civic culture: Political attitudes and democracy in five nations. Princeton, NJ: Princeton University Press.

Baasch, S., \& Blöbaum, A. (2017). Umweltbezogene Partizipation als gesellschaftliche und methodische Herausforderung [Environmental participation as a societal and methodological challenge]. Umweltpsychologie, 21(2), 11-33.

Baker, K. E. (2011). Understanding the local food phenomenon: Academic discourse, analytical concepts, and an investigation of local food initiatives. Explorations in Anthropology, 11(1), 3-24.

Baldy, J. (2019). Framing a sustainable local food system-How smaller cities in southern Germany are facing a new policy issue. Sustainability, 11(6), 1712.

Barber, B. R. (1984). Strong democracy: Participatory politics for a new age. Berkeley, CA: University of California Press.

Benford, R. D., \& Snow, D. A. (2000). Framing processes and social movement: An Overview and Assessment. Annual Review of Sociology, 26(1), 611-639.

Booth, S., \& Coveney, J. (2015). Food democracy: From consumer to food citizen. Singapore: Springer.

Clark, J. K. (2018). From civic group to advocacy coalition: Using a food policy audit as a tool for change. Journal 
of Agriculture, Food Systems, and Community Development, 8(1), 21-38.

Cretella, A., \& Buenger, M. S. (2016). Food as creative city politics in the city of Rotterdam. Cities, 51, 1-10.

Fischer, F. (2006). Participatory governance as deliberative empowerment. The American Review of Public Administration, 36(1), 19-40.

Fischer, F. (2012). Participatory governance: From theory to practice. In D. Lēwî-Faur (Ed.), The Oxford handbook of governance (pp. 475-471). Oxford: Oxford University Press.

Hassanein, N. (2003). Practicing food democracy: A pragmatic politics of transformation. Journal of Rural Studies, 19, 77-86.

Hassanein, N. (2008). Locating food democracy: Theoretical and practical ingredients. Journal of Hunger \& Environmental Nutrition, 3(2/3), 286-308.

Hebinck, A., \& Page, D. (2017). Processes of participation in the development of urban food strategies: A comparative assessment of Exeter and Eindhoven. Sustainability, 9(6), 931.

Johnston, J., Biro, A., \& MacKendrick, N. (2009). Lost in the supermarket: The corporate-organic foodscape and the struggle for food democracy. Antipode, 41(3), 509-532.

Kruse, J. (2015). Qualitative Interviewforschung: Ein integrativer Ansatz [Qualitative interview research: An integrative approach]. Weinheim: Beltz Juventa.

Lang, T. (1998). Towards a food democracy. In S. Griffiths \& J. Wallace (Eds.), Consuming passions: Food in the age of anxiety (pp. 13-23). Manchester: Mandolin.

Lang, T. (1999). Food policy for the 21st century: Can it be both radical and reasonable? In M. Koc, (Ed.), For hunger-proof cities: Sustainable urban food systems (pp. 216-224). Ottawa: International Development Research Centre.

Lang, T. (2005). Food control or food democracy? Reengaging nutrition with society and the environment. Public Health Nutrition, 8(6A), 730-737.

Lang, T., \& Barling, D. (2012). Food security and sustainability: Reformulating the debate. The Geographical Journal, 178(4), 313-326.

Lang, T., Barling, D., \& Caraher, M. (2009). Food policy: Integrating health, environment and society. Oxford: Oxford University Press.

Mendes, W. (2008). Implementing social and environmental policies in cities: The case of food policy in Vancouver, Canada. International Journal of Urban and Regional Research, 32(4), 942-967.

Paasi, A. (2009). The resurgence of the 'region' and 'regional identity': Theoretical perspectives and empirical observations on regional dynamics in Europe. Review of International Studies, 35(S1), 121-146.

Perrett, A., \& Jackson, C. (2015). Local food, food democ- racy, and food hubs. Journal of Agriculture, Food Systems, and Community Development, 6(1), 7-18.

Przyborski, A., \& Wohlrab-Sahr, M. (2014). Qualitative Sozialforschung: Ein Arbeitsbuch [Qualitative social research: A workbook]. Munich: Oldenbourg.

Renting, H., Schermer, M., \& Rossi, A. (2012). Building food democracy: Exploring civic food networks and newly emerging forms of food citizenship. International Journal of Sociology of Agriculture and Food, 19(3), 289-307.

Schaal, G. S., \& Wilhelm, F. (2018). Deliberative Minipublics. Zur Notwendigkeit einer Theorie der politischen Legitimation von eingebetteten deliberativen Systemen [Deliberative minipublics: The necessity of a theory of political legitimation of embedded deliberative systems]. In W. Thaa \& C. Volk (Eds.), Formwandel der Demokratie [Change of form of democracy] (pp. 199-221). Baden-Baden: Nomos Verlagsgesellschaft.

Schiff, R. (2008). The role of food policy councils in developing sustainable food systems. Journal of Hunger \& Environmental Nutrition, 3(2/3), 206-228.

Seyfang, G. (2006). Ecological citizenship and sustainable consumption: Examining local organic food networks. Journal of Rural Studies, 22, 383-395.

Sieveking, A. (2019). Food policy councils as loci for practising food democracy? Insights from the case of Oldenburg, Germany. Politics and Governance, 7(4), 48-58.

Turnhout, E., van Bommel, S., \& Aarts, N. (2010). How participation creates citizens: Participatory governance as performative practice. Ecology and Society, 15(4), 26.

van de Griend, J., Duncan, J., \& Wiskerke, J. S. C. (2019). How civil servants frame participation: Balancing municipal responsibility with citizen initiative in Ede's food policy. Politics and Governance, 7(4), 59-67.

van der Heijden, J. (2018). City and subnational governance. In A. Jordan, D. Huitema, H. van Asselt, \& J. Forster (Eds.), Governing climate change (pp. 81-96). Cambridge: Cambridge University Press.

van Hulst, M., \& Yanow, D. (2016). From policy "frames" to "framing": Theorizing a more dynamic, political approach. American Review of Public Administration, 46(1), 92-112.

Walk, H. (2008). Partizipative Governance: Beteiligungsformen und Beteiligungsrechte im Mehrebenensystem der Klimapolitik [Participatory governance: Forms and rights of participation in the multi-level system of climate policy]. Wiesbaden: VS Verlag für Sozialwissenschaften.

Wilkins, J. L. (2005). Eating right here: Moving from consumer to food citizen. Agriculture and Human Values, 22, 269-273. 


\section{About the Authors}

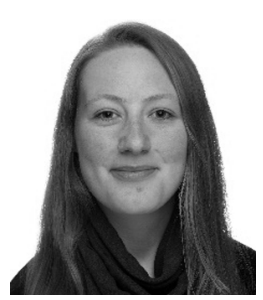

Jana Baldy, University of Freiburg, Research Fellow at the Chair of Forest and Environmental Policy. She is part of the joint research project KERNiG founded by the Federal Ministry of Education and Research (BMBF-Bundesministerium für Bildung und Forschung). Her research interests include environmental policy, food policy, gender studies and qualitative social research.

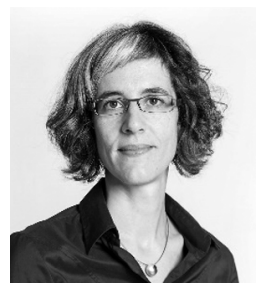

Sylvia Kruse, University of Freiburg, Lecturer and Senior Researcher at the Chair of Forest and Environmental Policy. She is part of the joint research project KERNiG. Her research field covers environmental policy and planning focusing on sustainable transformation, water management and climate change. 


\section{Annexes}

Annex 1. Overview of the participation processes in A-Town.

\begin{tabular}{ll}
\hline Format within the participation process & Participants \\
\hline 1. Civil dialog, 23.03.2017 & 9 citizens \\
\hline 2. Civil dialog, 06.04.2017 & 18 citizens \\
\hline 1. Expert dialog, 19.01.2017 & $\begin{array}{l}24 \text { participants: } 14 \text { local economy, } 4 \text { social agencies, } 3 \text { members of the city } \\
\text { council, } 2 \text { city administration, } 1 \text { economic alliance }\end{array}$ \\
\hline 2. Expert dialog, 21.02.2017 & $\begin{array}{l}15 \text { participants: } 8 \text { local economy, } 1 \text { members of the city council, } 2 \text { social } \\
\text { agency, } 1 \text { administration, } 1 \text { civil society, } 2 \text { economic alliance }\end{array}$ \\
\hline 3. Combined expert and civil dialog, & $\begin{array}{l}12 \text { participants: } 7 \text { citizens, } 3 \text { members of the city council, } 2 \text { local economy } \\
\text { 30.05.2017 }\end{array}$ \\
\hline $\begin{array}{l}\text { 1. Steering group meeting, 20.01.2017 } \\
\text { city council }\end{array}$ \\
\hline 2. Steering group meeting, 13.07.2017 & $\begin{array}{l}6 \text { participants: } 2 \text { administrative staff, } 1 \text { mayor and } 3 \text { members of the } \\
\text { city council }\end{array}$ \\
\hline
\end{tabular}

Annex 2. Overview of the participation processes in B-Town.

\begin{tabular}{ll}
\hline Format within the participation process & Participants \\
\hline 1. Civil dialog, 30.03.2017 & 15 citizens \\
\hline 2. Civil dialog, 03.05.2017 & 16 citizens \\
\hline 1. Expert dialog, 03.04.2017 & $\begin{array}{l}7 \text { participants: } 4 \text { local economy, } 2 \text { environmental organization and } \\
1 \text { social agencies }\end{array}$ \\
\hline 2. Expert dialog, 26.04.2017 & $\begin{array}{l}10 \text { participants: } 5 \text { local economy, } 3 \text { environmental organization and } \\
2 \text { social agencies }\end{array}$ \\
\hline 3. Combined expert and civil dialog, & 4 participants: 3 environmental organization and 1 local economy \\
20.06.2017 & \\
\hline 1. Steering group meeting, 11.04.2017 & $\begin{array}{l}4 \text { participants: } 3 \text { members of the city council, } 1 \text { former member of the } \\
\text { city council }\end{array}$ \\
\hline 2. Steering group meeting, 25.07.2017 & 4 participants: 2 administrative staff, 1 member of the city council, \\
\end{tabular}


Annex 3. Overview of the interviewees in A-Town.

\begin{tabular}{|c|c|c|c|c|}
\hline Type of actor & Shortcut & $\begin{array}{l}\text { Participant of the } \\
\text { civil dialog }\end{array}$ & $\begin{array}{l}\text { Participant of the } \\
\text { expert dialog }\end{array}$ & $\begin{array}{l}\text { Participant of the steering } \\
\text { group meeting }\end{array}$ \\
\hline \multirow[t]{4}{*}{ City administration } & A2 & & & \\
\hline & A6 & & & $x$ \\
\hline & A15 & & $x$ & \\
\hline & A17 & & & \\
\hline \multirow[t]{7}{*}{ City Council } & A4 & & $x$ & \\
\hline & A9 & & & \\
\hline & A10 & $x$ & $x$ & \\
\hline & A11 & & & $x$ \\
\hline & A12 & & & \\
\hline & A18 & & & \\
\hline & A20 & $x$ & $x$ & \\
\hline \multirow{7}{*}{ Local economy } & A4 & & $x$ & \\
\hline & A5 & & & \\
\hline & A16 & & $x$ & \\
\hline & $\mathrm{A} 20$ & $x$ & $x$ & \\
\hline & A22 & & $x$ & \\
\hline & A23 & & $x$ & \\
\hline & A24 & & & \\
\hline \multirow[t]{4}{*}{ Social agency } & A8_1 & & $x$ & \\
\hline & A8_2 & & $x$ & \\
\hline & A9 & & & \\
\hline & A11 & & & $x$ \\
\hline \multirow[t]{2}{*}{ Civil society } & A13 & $x$ & & \\
\hline & A14 & $x$ & & \\
\hline Economic alliance & A19 & & $x$ & \\
\hline Politician & A25 & & & \\
\hline
\end{tabular}




\section{COGITATIO}

Annex 4. Overview of the interviewees in B-Town.

\begin{tabular}{|c|c|c|c|c|}
\hline Type of actor & Shortcut & $\begin{array}{l}\text { Participant of the } \\
\text { civil dialog }\end{array}$ & $\begin{array}{l}\text { Participant of the } \\
\text { expert dialog }\end{array}$ & $\begin{array}{l}\text { Participant of the steering } \\
\text { group meeting }\end{array}$ \\
\hline \multirow[t]{3}{*}{ City administration } & B13 & & & \\
\hline & B15 & & & $\mathrm{x}$ \\
\hline & B19 & & & \\
\hline District administration & B24 & & & \\
\hline \multirow[t]{4}{*}{ City Council } & B8 & & & $\mathrm{x}$ \\
\hline & B9 & & & $\mathrm{x}$ \\
\hline & B14 & & & $\mathrm{x}$ \\
\hline & B22 & & & \\
\hline Former member of the city council & B4 & $\mathrm{x}$ & & $\mathrm{X}$ \\
\hline \multirow[t]{4}{*}{ Local economy } & B8 & & & $x$ \\
\hline & B9 & & & $\mathrm{x}$ \\
\hline & B18 & $\mathrm{x}$ & $x$ & \\
\hline & B25 & & $x$ & \\
\hline \multirow[t]{2}{*}{ Social agency } & B14 & & & $x$ \\
\hline & B21 & & $\mathrm{X}$ & \\
\hline Civil society & B7_2 & $x$ & & \\
\hline \multirow[t]{4}{*}{ Environmental organization } & B5 & $x$ & & \\
\hline & B7_1 & $x$ & & \\
\hline & B12_1 & $\mathrm{x}$ & $x$ & \\
\hline & B12_2 & $x$ & $x$ & \\
\hline
\end{tabular}

